\title{
Systolic Blood Pressure Levels Associated with Cardiovascular Events and All-cause Mortality: Results from the REGARDS Study
}

\section{Aronow WS*}

Cardiology Division, Department of Medicine, Westchester Medical Center/ New York Medical College, Valhalla, NY, USA

The reasons for Geographic and Racial Differences in Stroke (REGARDS) study is a population-based observational study of 30, 239 persons aged 45 years and older living in the stroke belt and stroke buckle of the United States. The stroke belt and stroke buckle include North Carolina, South Carolina, Georgia, Alabama, Mississippi, Tennessee, Arkansas, and Louisiana. This editorial will discuss data from the REGARDS study in 4,181 adults aged 55 to 74 years, 3,767 adults aged 65 to 74 years, and 1,839 adults aged 75 years and older, mean age 79.3 years, taking antihypertensive medication [1]. The persons aged 55 to 64 years included $38 \%$ men, $62 \%$ women, and $56.2 \%$ blacks. The persons aged 65 to 74 years included $39.3 \%$ men, $60.7 \%$ women, and $50 \%$ blacks. The persons aged 75 years and older included $36.9 \%$ men, $63.1 \%$ women, and $45.4 \%$ blacks. Cardiovascular disease events included the first occurrence of a coronary heart disease or stroke event. Median follow-up was 4.5 years for cardiovascular disease, 4.5 years for coronary heart disease, 5.7 years for stroke, and 6.0 years for all-cause mortality [1].

For persons aged 55 to 64 years, a systolic blood pressure below $140 \mathrm{~mm} \mathrm{Hg}$ was associated with the lowest incidence of cardiovascular disease, coronary heart disease, stroke, and all-cause mortality, with numerically the highest risk at a systolic blood pressure of 140 to 149 $\mathrm{mm} \mathrm{Hg}$, and especially for a systolic blood pressure of $150 \mathrm{~mm} \mathrm{Hg}$ and higher [1]. The risk of recurrent falls was also increased at systolic blood pressure levels of $150 \mathrm{~mm} \mathrm{Hg}$ and higher [1].

For persons aged 65 to 74 years, there was a significant increased incidence of cardiovascular disease and of coronary heart disease at systolic blood pressure levels of $150 \mathrm{~mm} \mathrm{Hg}$ and higher, of stroke at systolic blood pressure levels of $130 \mathrm{~mm} \mathrm{Hg}$ and higher, and of allcause mortality at systolic blood pressure levels of $140 \mathrm{~mm} \mathrm{Hg}$ and higher [1]. In this age group, systolic blood pressure was not associated with recurrent falls [1].

For persons aged 75 years and older, there was a significant increased incidence of cardiovascular disease, coronary heart disease, and stroke at systolic blood pressure levels of $140 \mathrm{~mm} \mathrm{Hg}$ and higher [1]. The incidence of cardiovascular disease, coronary heart disease, stroke, all-cause mortality, and recurrent falls was significantly increased at systolic blood pressure levels below $120 \mathrm{~mm} \mathrm{Hg}$ [1].

These data from the REGARDS study support the recommendations from the American College of Cardiology Foundation 2011 expert consensus document on hypertension in the elderly [2]. These guidelines recommend reducing the systolic blood pressure to less than $140 \mathrm{~mm} \mathrm{Hg}$ in persons with hypertension aged younger than 80 years and to 140 to $145 \mathrm{~mm} \mathrm{Hg}$ if tolerated in persons aged 80 years and older [2]. The European Society of Hypertension/European Society of Cardiology 2013 guidelines recommend reducing the systolic blood pressure in fit persons younger than 80 years to less than $140 \mathrm{~mm} \mathrm{Hg}$ and in persons aged 80 years and older to between 140 and $150 \mathrm{~mm}$ $\mathrm{Hg}[3]$.

I disagree strongly with the 2014 guidelines report from the Eighth Joint National Committee (JNC 8) which recommends reducing the systolic blood pressure to less than $150 \mathrm{~mm} \mathrm{Hg}$ in persons aged 60 years and older with hypertension without diabetes mellitus or chronic kidney disease [4]. I agree with the JNC 8 minority report which recommends that the systolic blood pressure goal should be less than $140 \mathrm{~mm} \mathrm{Hg}$ in persons with hypertension younger than 80 years without diabetes mellitus or chronic kidney disease [5]. The data from the REGARDS study [1] support this recommendation.

Older persons with hypertension have the lowest rates of adequate blood pressure control and the highest incidence of cardiovascular events. Blood pressure is adequately controlled in $36 \%$ of men and $28 \%$ of women aged 60 to 79 years and in $38 \%$ of men and $23 \%$ of women aged 80 years and older [6]. I am very much concerned that the higher systolic blood pressure goal in persons aged 60 years and older without diabetes mellitus or chronic kidney disease recommended by the JNC 8 guidelines will lead to a higher incidence of cardiovascular events and mortality.

\section{References}

1. Banach M, Bromfield S, Howard G, Zanchetti A, Aronow WS, et al. (2014) Association of systolic blood pressure levels with cardiovascular events and all-cause mortality among older adults taking antihypertensive medication. Int J Cardiol 176: 219-226.

2. Aronow WS, Fleg JL, Pepine CJ, Artinian NT, Bakris G, et al. (2011) ACCF/AHA 2011 expert consensus document on hypertension in the elderly: a report of the American College of Cardiology Foundation Task Force on Clinical Expert Consensus Documents. Developed in collaboration with the American Academy of Neurology, American Geriatrics Society, American Society for Preventive Cardiology, American Society of Hypertension, American Society of Nephrology, Association of Black Cardiologists, and European Society of Hypertension. J Am Coll Cardiol 57: $2037-$ 2114.

3. Mancia G, Fagard R, Narkiewicz K, Redon J, Zanchetti A, et al. (2013) ESH/ESC guidelines for the management of arterial hypertension: the Task Force for the Management of Arterial Hypertension of the European Society of Hypertension (ESH) and of the European Society of Cardiology (ESC). Eur Heart J 34: 2159-2219.

4. James PA, Oparil S, Carter BL, Cushman WC, Dennison-Himmelfarb C, et al. (2014) evidence-based guideline for the management of high blood pressure in adults. Report From the Panel Members Appointed to the Eighth Joint National Committee (JNC 8). JAMA 311: 507-520.

5. Wright JT Jr, Fine LJ, Lackland DT, Ogedegbe G, Dennison-Himmelfarb C, et al (2014) Evidence supporting a systolic blood pressure goal of less than $150 \mathrm{~mm} \mathrm{Hg}$ in patients aged 60 years or older: the minority view. Ann Intern Med 160: 499-503.

6. Lloyd-Jones DM, Evans JC, Levy D (2005) Hypertension in adults across the age spectrum: current outcomes and control in the community. JAMA 294: 466-472.

*Corresponding author: Aronow WS, Cardiology Division, Department of Medicine, Westchester Medical Center/ New York Medical College, Valhalla, NY, USA, Tel: 914 - 493-5311; E-mail: wsaronow@aol.com

Received August 18, 2014; Accepted August 21, 2014; Published August 25 2014

Citation: Aronow WS (2014) Systolic Blood Pressure Levels Associated with Cardiovascular Events and All-cause Mortality: Results from the REGARDS Study. Cardiol Pharmacol 3: e126. doi:10.4172/2329-6607.1000e126

Copyright: () 2014 Aronow WS. This is an open-access article distributed under the terms of the Creative Commons Attribution License, which permits unrestricted use, distribution, and reproduction in any medium, provided the original author and source are credited. 